\title{
The Akt activation inhibitor TCN-P inhibits Akt phosphorylation by binding to the PH domain of Akt and blocking its recruitment to the plasma membrane
}

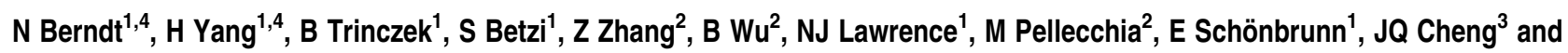 \\ SM Sebti ${ }^{\star, 1}$
}

Persistently hyperphosphorylated Akt contributes to human oncogenesis and resistance to therapy. Triciribine (TCN) phosphate (TCN-P), the active metabolite of the Akt phosphorylation inhibitor TCN, is in clinical trials, but the mechanism by which TCN-P inhibits Akt phosphorylation is unknown. Here we show that in vitro, TCN-P inhibits neither Akt activity nor the phosphorylation of Akt S473 and T308 by mammalian target of rapamycin or phosphoinositide-dependent kinase 1. However, in intact cells, TCN inhibits EGF-stimulated Akt recruitment to the plasma membrane and phosphorylation of Akt. Surface plasmon resonance shows that TCN, but not TCN, binds Akt-derived pleckstrin homology $(\mathrm{PH})$ domain $\left(K_{\mathrm{D}}: 690 \mathrm{nM}\right)$. Furthermore, nuclear magnetic resonance spectroscopy shows that TCN-P, but not TCN, binds to the PH domain in the vicinity of the PIP3-binding pocket. Finally, constitutively active Akt mutants, Akt1-T308D/S473D and myr-Akt1, but not the transforming mutant Akt1-E17K, are resistant to TCN and rescue from its inhibition of proliferation and induction of apoptosis. Thus, the results of our studies indicate that TCN-P binds to the PH domain of Akt and blocks its recruitment to the membrane, and that the subsequent inhibition of Akt phosphorylation contributes to TCN-P antiproliferative and proapoptotic activities, suggesting that this drug may be beneficial to patients whose tumors express persistently phosphorylated Akt.

Cell Death and Differentiation (2010) 17, 1795-1804; doi:10.1038/cdd.2010.63; published online 21 May 2010

The Ser/Thr-specific protein kinase Akt was discovered in $1991^{1-3}$ and has since emerged as an important promoter of tumor cell survival, proliferation as well as migration and invasion. ${ }^{4,5}$ In mammals, Akt is represented by three isoforms, which share $74 \%$ amino acid sequence identity. Despite this high degree of homology, Akt isoforms may have distinct roles in development and normal physiology. For example, targeted gene deletions in mice have shown that loss of Akt1 function results in smaller body size and significant growth defects. ${ }^{6,7}$ Mice lacking Akt2 are unable to maintain glucose homeostasis and are diabetic, ${ }^{8}$ whereas Akt3 knockout mice have smaller brains but are otherwise normal. ${ }^{9}$

For activity, Akt requires recruitment to the plasma membrane and subsequent phosphorylation at two critical sites, T308 and S473. These events are initiated by growth factors binding to their receptors, which activate phosphatidylinositol-3 kinase (PI3K) to convert phosphatidylinositol (4,5)-bisphosphate (PIP2) to phosphatidylinositol $(3,4,5)$-trisphosphate (PIP3). PIP3 recruits pleckstrin homology $(\mathrm{PH})$ domain-containing proteins such as Akt to the plasma membrane, where it is phosphorylated at T308 by phosphoinositide-dependent kinase 1 (PDK1). ${ }^{10}$ To be fully active, Akt also needs to be phosphorylated at S473. This site is phosphorylated by several kinases including DNA-dependent protein kinase (DNA-PK) ${ }^{11,12}$ and mammalian target of rapamycin (mTOR) complex 2 (mTORC2). ${ }^{13}$ Whereas mTORC2-mediated phosphorylation of $S 473$ occurs at the membrane in response to growth factors, ${ }^{13}$ DNA-PK phosphorylates $S 473$ in the nucleus in response to DNA damage. ${ }^{11,12}$ Whether phosphorylation at T308 and S473 in vivo occurs in a specific order is still controversial, ${ }^{5}$ but in vitro, T308 and S473 can be phosphorylated independently. ${ }^{14}$ Whereas the tumor suppressor phosphatase and tensin homologue (PTEN) antagonizes Akt signaling by dephosphorylating phosphoinositides, thereby preventing the activation of PDK1 and Akt, the mechanisms that directly terminate Akt signaling are not well characterized. pT308 is probably dephosphorylated by PP2A ${ }^{15}$ and pS473 dephosphorylation may involve $\mathrm{PP} 1^{16}$ and/or novel PP2C-like phosphatases termed PHLPP1 and 2. ${ }^{17}$

The PI3K/PTEN/Akt pathway is very frequently deregulated in human cancer, leading to persistent hyperphosphorylationhyperactivation of Akt. This can be due to persistent activation

\footnotetext{
${ }^{1}$ Drug Discovery Department, Moffitt Cancer Center, 12902 Magnolia Drive, Tampa, FL 33612, USA; ${ }^{2}$ Infectious and Inflammatory Disease Center, Sanford-Burnham Medical Research Institute, 10901 N Torrey Pines Road, La Jolla, CA 92037, USA and ${ }^{3}$ Molecular Oncology Department, Moffitt Cancer Center, 12902 Magnolia Drive, Tampa, FL 33612, USA

*Corresponding author: SM Sebti, Drug Discovery Department, Moffitt Cancer Center, 12902 Magnolia Drive, Tampa, FL 33612, USA. Tel: +813 7456734 ; Fax: + 813745 7648; E-mail: said.sebti@moffitt.org

${ }^{4}$ These authors contributed equally to this work.

Keywords: Akt; TCN-P; apoptosis; protein phosphorylation; surface plasmon resonance; nuclear magnetic resonance; protein-drug interactions

Abbreviations: DMSO, dimethylsulfoxide; GSK3, glycogen synthase kinase 3; IP4, inositol (1,3,4,5)-tetrakisphosphate; mTOR, mammalian target of rapamycin; mTORC2, mammalian target of rapamycin complex 2; PDK1, phosphoinositide-dependent kinase 1; PH, pleckstrin homology; PI3K, phosphatidylinositol-3 kinase; PIP2, phosphatidylinositol $(4,5)$-bisphosphate; PIP3, phosphatidylinositol $(3,4,5)$-trisphosphate; PTEN, phosphatase and tensin homologue; SPR, surface plasmon resonance; TCN, triciribine; TCN-P, triciribine phosphate

Received 22.1.10; revised 13.4.10; accepted 14.4.10; Edited by W El-Deiry; published online 21.5.10
} 
of receptor tyrosine kinases, activating mutations in $\mathrm{PI} 3 \mathrm{~K}$, inactivating mutations or deletion of PTEN,${ }^{18,19}$ overexpression of $\mathrm{Akt}^{20,21}$ or a transforming and rare Akt mutation (E17K). ${ }^{22}$ Nonetheless, the specific roles of Akt isoforms in tumorigenesis are poorly understood. For instance, Akt1 is persistently activated in many cancers, and loss of Akt1 expression by antisense oligonucleotides results in inhibition of anchorageindependent growth and induction of apoptosis. ${ }^{23}$ Overexpression of Akt2, but not Akt1 or Akt3, results in an increase of PI3K-dependent invasion and metastasis of breast and ovarian cancer cells. ${ }^{24}$ Increased Akt3 expression and loss of PTEN result in the development of melanoma, and Akt3 siRNA stimulates apoptosis and inhibits melanoma development. ${ }^{25}$

Akt contributes to malignant transformation and/or tumor progression by acting on many substrates (for recent reviews see refs. ${ }^{4,26-28}$ ) including IKK $\alpha$, Bad, caspase-9 and forkhead transcription factors. Intriguingly, Akt phosphorylates Mdm2, thereby stimulating the subsequent degradation of p53. Furthermore, Akt has a direct role in promoting cell-cycle progression by phosphorylating p21Cip1 and p27Kip1. Also, when growth factors are present, Akt can inhibit TSC1/2, eventually causing stimulation of mTOR, an important kinase that stimulates cell growth through promoting protein synthesis through ribosomal protein S6 kinase.

Because Akt is intimately involved in mediating many of the hallmarks of cancer, Akt has become a major anticancer drug target. ${ }^{18,19,29,30}$ Recently, we have discovered an Akt phosphorylation inhibitor, triciribine (TCN) and its active metabolite TCN-P, through screening the $\mathrm{NCl}$ Diversity Set. ${ }^{31}$ This compound does not inhibit Akt kinase activity per se, but in whole cells prevents phosphorylation of Akt1, Akt2 or Akt3. ${ }^{31}$ Furthermore, TCN does not inhibit PI3K, PDK1 and other protein kinases, but inhibits proliferation, induces apoptosis and inhibits tumor growth in animals much more potently in tumors that contain persistently hyperphosphorylated Akt, suggesting that TCN is a selective Akt activation inhibitor. ${ }^{31}$ It is important to point out that TCN is a tricyclic nucleoside, ${ }^{32}$ which, once inside cells, is phosphorylated to its monophosphate derivative, TCN-P, by adenosine kinase. TCN-P is the active metabolite of TCN, as in cells lacking adenosine kinase it is 5000 -fold less active. ${ }^{33}$ TCN-P is presently undergoing human clinical trials in patients whose tumors have high levels of phosphorylated Akt. ${ }^{34}$ However, the mechanism by which TCN-P inhibits the phosphorylation of Akt is not known. In this study, using biochemical and cell biological studies, surface plasmon resonance (SPR) and nuclear magnetic resonance (NMR), we show that TCN-P, but not TCN, binds to the PH domain of Akt and prevents its recruitment to the plasma membrane and subsequent phosphorylation at T308 and S473. We also show that constitutively active Akt mutants, Akt1-T308D/ S473D and myr-Akt, but not Akt1-E17K, rescue cells from TCN-P effects suggesting that the ability of TCN-P to inhibit tumor cell growth is due to its ability to prevent Akt phosphorylation.

\section{Results}

TCN-P inhibits in vitro neither Akt kinase activity nor the phosphorylation of purified Akt by PDK1 and mTORC2. TCN-P inhibits the phosphorylation of Akt in whole cells, suppresses tumor growth and induces apoptosis selectively in tumors that have persistently hyperphosphorylated Akt compared with those that do not. ${ }^{31}$ This prompted a clinical trial in a population of patients whose tumors contain persistently hyperphosphorylated Akt. $^{34}$ Critical to the clinical development of TCN-P as a targeted agent is to understand the biochemical mechanism by which it inhibits the phosphorylation of Akt. We have undertaken several biochemical, biophysical and cell biological studies to address this important question. First we determined whether in vitro TCN-P inhibits Akt kinase activity or the ability of PDK1 and mTOR to phosphorylate Akt at T308 and S473, respectively, the two phosphorylation sites required for full activation of Akt. TCN-P did not inhibit the ability of Akt1 to phosphorylate its substrate glycogen synthase kinase 3 (GSK3)- $\beta$ in vitro (Figure 1a). Furthermore, purified PDK1
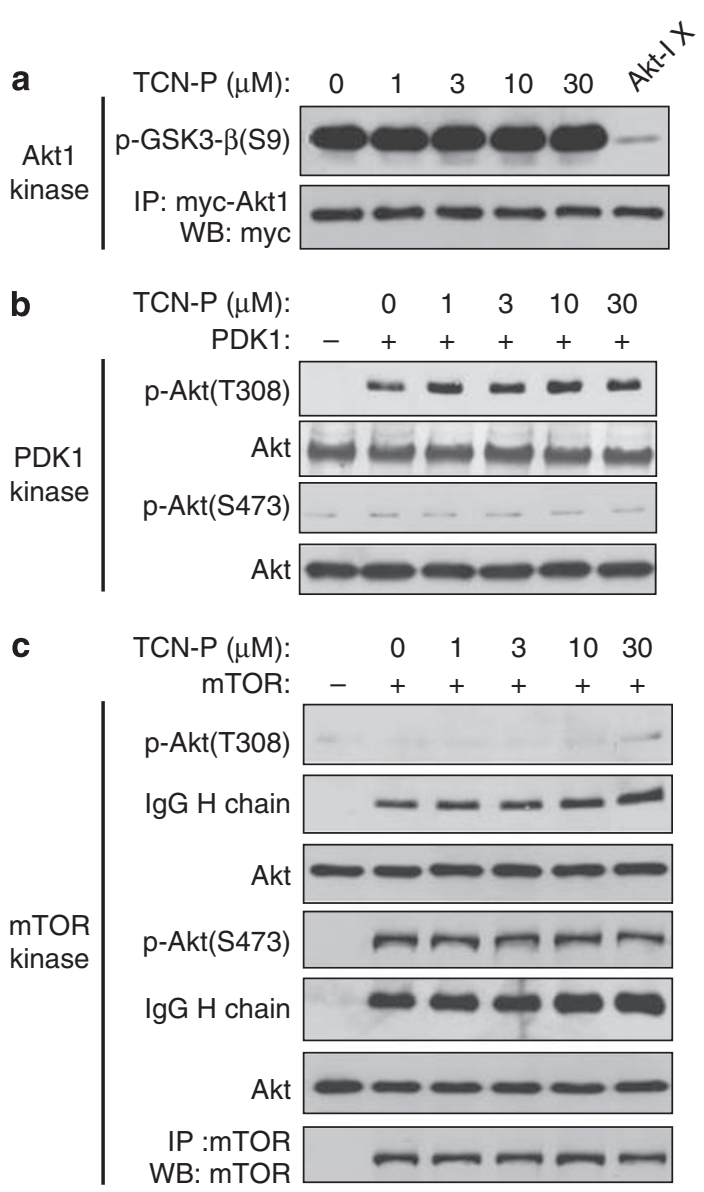

Figure 1 TCN-P does not inhibit the activity and phosphorylation of purified Akt in vitro. Kinase assays were performed with purified or immunoprecipitated proteins in the presence of $200 \mu \mathrm{M}$ ATP in the absence or presence of increasing TCN-P concentrations, followed by western blotting with the indicated antibodies as described in Materials and Methods. All experiments were performed independently at least three times. (a) Up to $30 \mu \mathrm{M}$ TCN-P does not inhibit in vitro the kinase activity (as measured by phosphorylation of the substrate GSK3- $\beta$ ) of Akt1 immunoprecipitated from HEK293T cells transfected with Myc-tagged Akt. Exposure to $10 \mu \mathrm{M}$ Akt inhibitor $\mathrm{X}$ (lane 6) shows that Akt activity could be inhibited efficiently. (b) Up to $30 \mu \mathrm{M}$ TCN-P does not interfere with the phosphorylation of Akt1 at T308 by PDK-1. (c) Up to $30 \mu \mathrm{M}$ TCN-P does not interfere with the phosphorylation of Akt1 at $S 473$ by immunoprecipitated mTOR 
and immunoprecipitated mTOR readily phosphorylated purified Akt1 at T308 and $\mathrm{S} 473$ in vitro, respectively, regardless of whether TCN-P was present in the reaction mixture or not (Figure $1 \mathrm{~b}$ and $\mathrm{c}$ ). These in vitro results show that TCN-P does not inhibit Akt kinase activity and does not directly interfere with the phosphorylation of Akt by either PDK-1 or mTOR.

TCN prevents EGF-mediated Akt recruitment to the plasma membrane. Because TCN-P inhibits the phosphorylation of Akt in intact cells but not in vitro, we reasoned that a possible mechanism of action of TCN-P could be to prevent the translocation of Akt from the cytosol to the plasma membrane. To explore this possibility, we used two approaches, immunofluorescence and subcellular fractionation/western blotting. First, we transfected MDAMB-468 cells with Myc-tagged Akt1, starved them, treated them with EGF, TCN or both and processed them for immunofluorescence. A major proportion (69.4\%) of vehicletreated starved MDA-MB-468 cells contained Akt in the cytosol (Figure 2a and b). However, these starved MDA-MB468 cells contained $30.6 \pm 5.7 \%$ of Akt in the plasma membrane (Figure $2 \mathrm{~b}$ ). Treatment of these starved cells with TCN alone resulted in a decreased amount of cells with Akt in the plasma membrane from $30.6 \pm 5.7$ to $14.3 \pm 3.0 \%$. In contrast, stimulation with EGF in the absence of TCN resulted in $100 \%$ of the cells with Akt in the plasma membrane. Pretreatment of the cells with TCN before EGF stimulation dramatically reduced the percentage of cells with Akt in the plasma membrane from 100 to $20.0 \pm 5.0 \%$ (Figure 2a and b). Further, we used subcellular fractionation to confirm these results. Consistent with the immunofluorescence data, TCN inhibited the ability of EGF to induce Akt recruitment to the plasma membrane in MDAMB-468 cells (Figure 2c).

TCN-P, but not TCN, binds to the PH domain of Akt as shown by SPR. The results described in Figures 1 and 2 suggest that a possible mechanism by which TCN inhibits Akt phosphorylation in intact cells is that TCN-P binds to the $\mathrm{PH}$ domain of Akt, thereby preventing its recruitment to the plasma membrane. To explore this possibility, we carried out binding experiments using SPR and NMR with Akt-derived $\mathrm{PH}$ domain. First, we determined by SPR whether TCN-P and/or TCN bind the $\mathrm{PH}$ domain of Akt. Figure 3a shows a typical sensorgram obtained with six TCN-P concentrations (46 nM to $11.1 \mu \mathrm{M})$, indicating that TCN-P bound to the $\mathrm{PH}$ domain of Akt in a dose-dependent manner. TCN-P bound to the Akt $\mathrm{PH}$ domain with a $k_{\mathrm{a}}$ of 366 (per Ms), a $k_{\mathrm{d}}$ of $2.52 \times 10^{-4}$ (per second) and a $K_{\mathrm{D}}$ of $690 \mathrm{nM}$ (Figure $3 \mathrm{a}$ ). In contrast, TCN did not bind the Akt PH domain (Figure $3 b$ ). Figure $3 \mathrm{c}$ shows the responses after a contact time of $300 \mathrm{~s}$ for TCN-P and TCN as a function of their concentration, further showing that TCN-P, but not TCN, binds to the Akt PH domain. To validate these results, we carried out several control experiments. Table 1 summarizes the kinetic data obtained with several compounds and the Akt-PH domain. As a positive control, we used Akt inhibitor $\mathrm{VI}$, a peptide derived from the TCL1 oncoprotein that was reported to bind the $\mathrm{PH}$ domain of $\mathrm{Akt}^{35}$ and found in our experiments that a
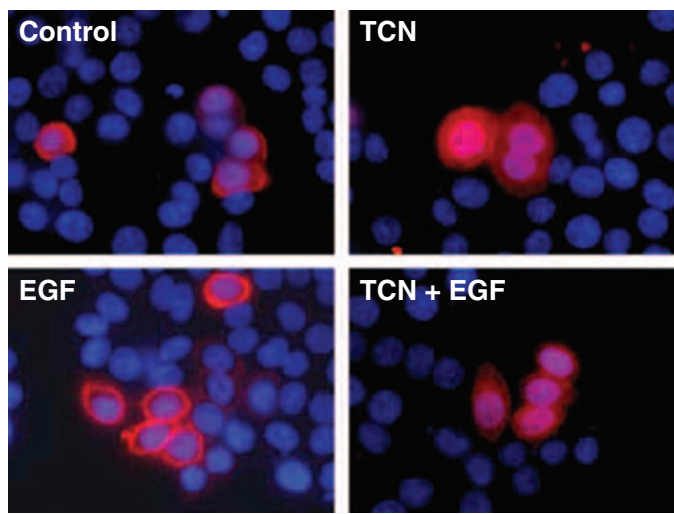

b

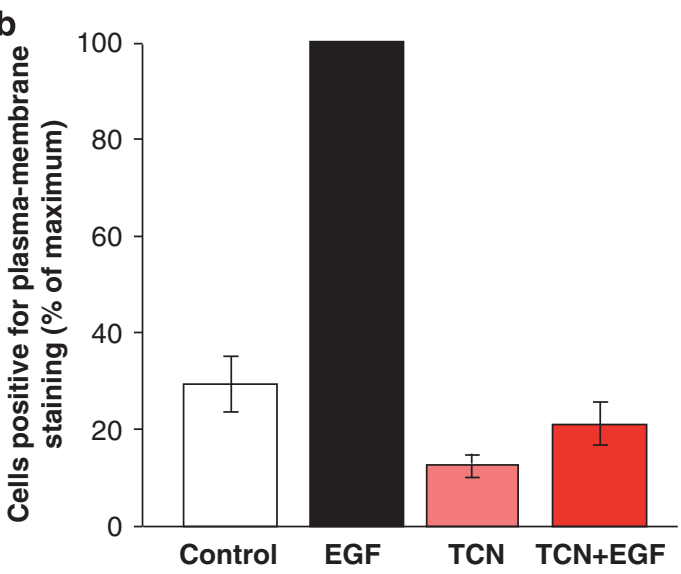

C

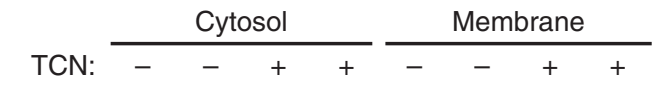

$\mathrm{EGF}:-\quad+\quad-\quad+\quad-\quad+\quad-\quad+$

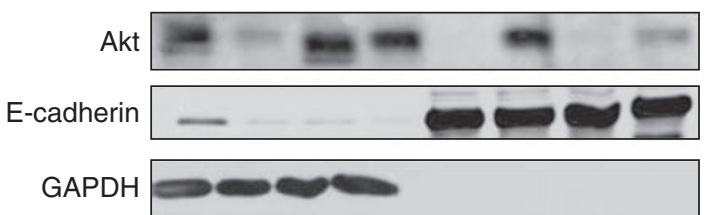

Figure 2 TCN inhibits EGF-induced recruitment of AKT1 to the plasma membrane. (a-c) Serum-starved MDA-MB-468 cells exogenously expressing Myc-tagged wild-type Akt1 were treated with vehicle, EGF, TCN or TCN + EGF, and further analyzed by immunofluorescence $(\mathbf{a}, \mathbf{b})$ and subcellular fractionation (c) as described in Materials and Methods. (a) Fluorescent images representative of three independent experiments show that in control cells, Akt (red) was mainly found in the cytosol, whereas in EGF-stimulated cells, Akt clearly relocated to the membrane. Cells treated with TCN showed cytosolic staining with or without stimulation by EGF. (b) Quantification of membrane localization of Akt1 was carried out as follows. Approximately 100 cells were scored in each of three randomly selected fields. Results are presented as percentage of Myc-Akt1-transfected cells that are positive for plasma membrane-located Akt1. Each column represents the mean of three independent experiments \pm S.D. (c) Membrane and cytosolic fractions were prepared as described in Materials and Methods and analyzed by western blotting with the indicated antibodies (representative of two independent experiments)

it binds the Akt-derived $\mathrm{PH}$ domain with a $K_{\mathrm{D}}$ of $1.4 \mu \mathrm{M}$ (Table 1). Furthermore, PIP3, the plasma membrane lipid that recruits Akt to the plasma membrane, bound the Akt-PH domain with a $k_{\mathrm{a}}$ of 4251 (per Ms), a $k_{\mathrm{d}}$ of $2.05 \times 10^{-4}$ (per second) and a $K_{\mathrm{D}}$ of $48 \mathrm{nM}$ (Table 1$)$. 

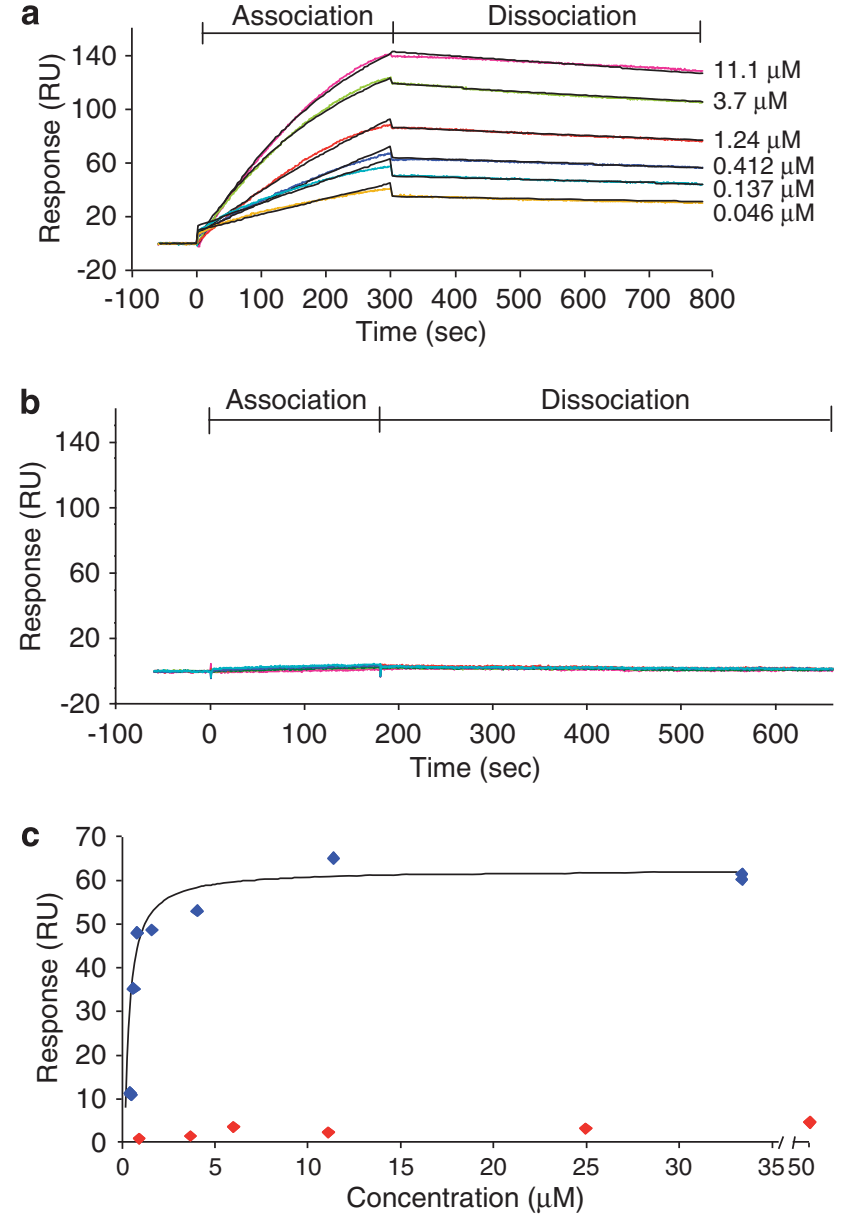

Figure 3 TCN-P, but not TCN, binds to the PH domain of Akt. The interaction between TCN and TCN-P, and Akt PH domain was investigated with the Biacore T100 system. The graphs shown are representative of at least two independent experiments. (a, b) Akt1-derived PH domain was immobilized to the surface through ligand thiol coupling as described in Materials and Methods. (a) Representative example of sensorgrams for the interaction between TCN-P and Akt1-PH domains, showing an increased response with increasing concentrations. (b) Representative example of sensorgrams for the interaction between TCN and Akt1-PH domain, indicating that there is no significant interaction. (c) Dose-dependent interaction at $300 \mathrm{~s}$ with NTA-captured His-tagged Akt1 PH domain was observed between TCN-P (blue), but not TCN (red)

Table 1 Interactions between TCNP and Akt1-derived PH domain, immobilized through thiol coupling

\begin{tabular}{llccc}
\hline Compound & $\boldsymbol{R}_{\text {exp }} / \boldsymbol{R}_{\max }$ & $\boldsymbol{k}_{\mathrm{a}}$ (per Ms) & $\boldsymbol{k}_{\mathrm{d}}$ (per s) & $\boldsymbol{K}_{\mathbf{D}}$ \\
\hline TCN-P & $80 / 91$ & 366 & 0.000252 & $690 \mathrm{nM}$ \\
PIP3 & $31 / 186$ & 4251 & 0.000205 & $48 \mathrm{nM}$ \\
Akt-I VI & $48 / 422$ & 80 & 0.000116 & $1.4 \mu \mathrm{M}$ \\
\hline
\end{tabular}

Ligand-binding studies by NMR chemical shift mapping reveal that TCN-P, but not TCN, binds Akt-PH domain. To further characterize the binding properties of TCN-P and TCN to the Akt PH domain, we conducted ligand-binding studies using NMR. Chemical shift mapping data suggest that Akt-PH domain residues in the PIP3-binding pocket ${ }^{36,37}$ were perturbed on complexation with TCN-P, but perturbation also extended outside this region (Figure 4a and b), possibly due to some small conformational changes upon binding. For example, G16, I19, R23, R25 and I36 all show chemical shift perturbation. Conversely, no appreciable chemical shift perturbation could be observed with the compound TCN (Figure $4 a$ and b). This is consistent with the SPR results and suggests that the presence of the phosphate group is essential for binding (see more below).

Hence, on the basis of chemical shift mapping studies, we performed molecular docking studies to provide further possible binding poses of TCN-P in the PIP3-binding site of Akt $\mathrm{PH}$ domain. A possible binding mode for the compound was obtained using the program GOLD version 2.1 (CCDC Software Ltd., Cambridge, UK) and the structure of Akt PH domain (PDB code: $1 \mathrm{H} 10$ ). ${ }^{36}$ The TCN-P-binding site was defined within a $15 \AA$ radius around the residue $\mathrm{K} 14,{ }^{36}$ located at the PIP3-binding site. A total 100 runs were performed and the conformation of TCN-P with the best GOLD score is shown in Figure 4c, along with the binding mode of inositol $(1,3,4,5)$-tetrakisphosphate (IP4), the well-accepted head group of PIP3 that binds to the Akt PH domain ${ }^{36,37}$ (Figure 4d). For comparison, Figure $4 \mathrm{e}$ and $\mathrm{f}$ shows spacefilling models and the interacting amino-acid residues for both TCN-P and PIP3. Although ultimately X-ray diffraction studies will be needed to further delineate the intermolecular contacts at the atomic level, the docking pose obtained further suggests that TCN-P partially mimics the binding interactions provided by PIP3. Indeed, in the docking models, the phosphate of TCN-P is positioned at the location of the D3 phosphate of PIP3 and is surrounded by the residues K14, R23, R25 and N53 (Figure 4e and f). These are the same residues that have been shown to interact with the D3 phosphate of PIP3 in the crystal structure of Akt PH domain and PIP3 ${ }^{36}$ Furthermore, the five-membered sugar ring of TCN-P (Figure $4 \mathrm{C}$ and e) can almost be superimposed to the six-membered ring of PIP3 (Figure $4 d$ and f).

Constitutively active Akt1-T308D/S473D and myr-Akt1 but not Akt1-E17K rescue from TCN-mediated inhibition of Akt activation, loss of cell viability and induction of apoptosis. The results from Figures 1-4 show that TCN-P binds to the $\mathrm{PH}$ domain of Akt and inhibits its recruitment to the plasma membrane, and suggest this as a mechanism by which TCN treatment of cells inhibits Akt phosphorylation and subsequent activation. If this is the case, we reasoned that an Akt mutant that no longer requires recruitment to the plasma membrane and activation by phosphorylation would be resistant to TCN-P, and rescues cells from TCN-Pmediated inhibition of proliferation and induction of apoptosis. To evaluate this possibility, we stably expressed in COS-7 cells either Myc-tagged wild-type Akt1 or Myc-tagged Akt1-T308D/S473D (Akt1-DD), a constitutively active Akt mutant that does not require plasma membrane binding or phosphorylation at T308 and S473 for activation. Both wildtype Akt1- and Akt1-DD-, but not the vector-transfected cells, expressed the Myc-tagged Akt proteins (Figure 5a, left panel). First, we determined whether the Akt1-DD kinase activity in intact cells is resistant to TCN. To this end, we treated wild-type Akt1 and Akt1-DD stably expressing cells with TCN, immunoprecipitated Akt with Myc antibody and 

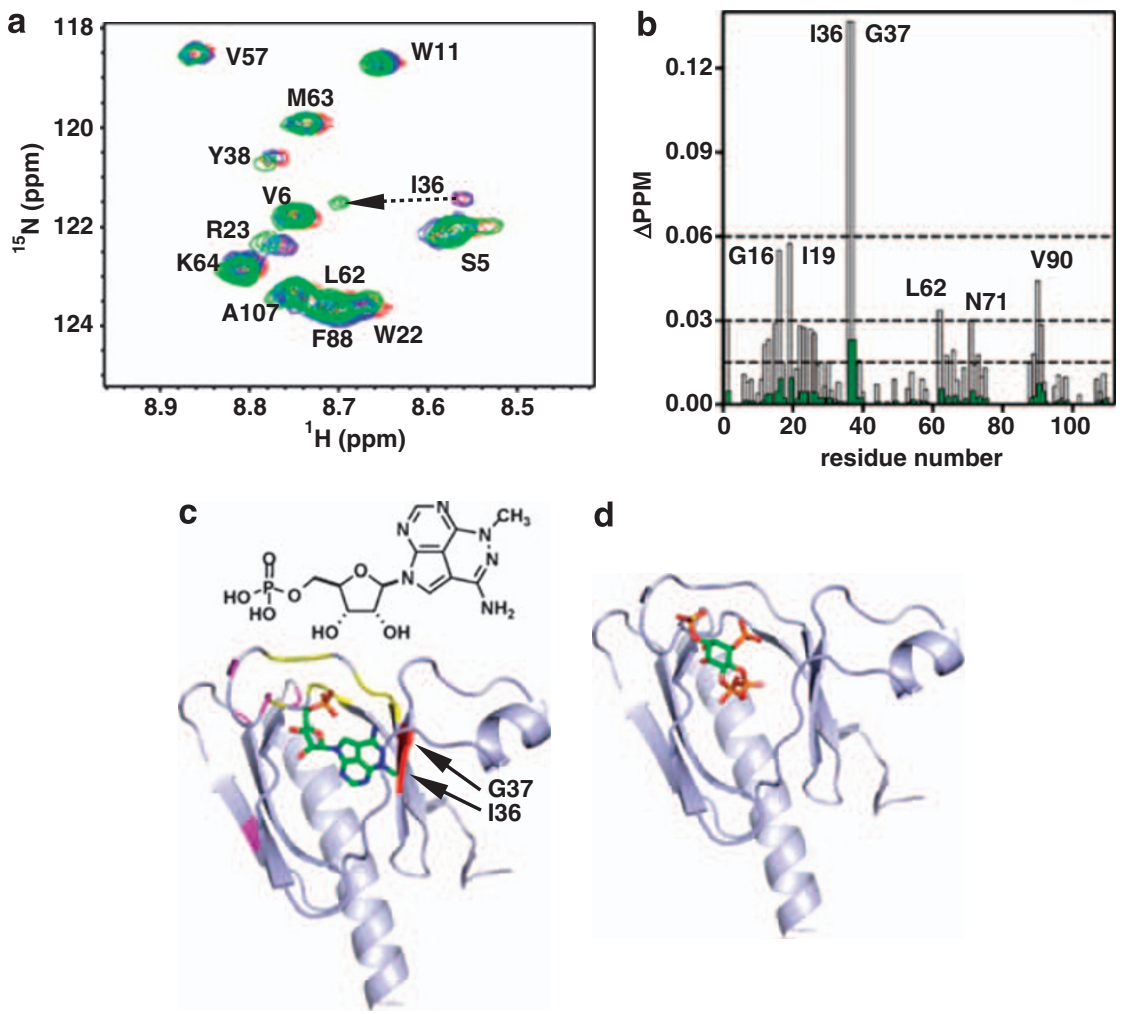

d
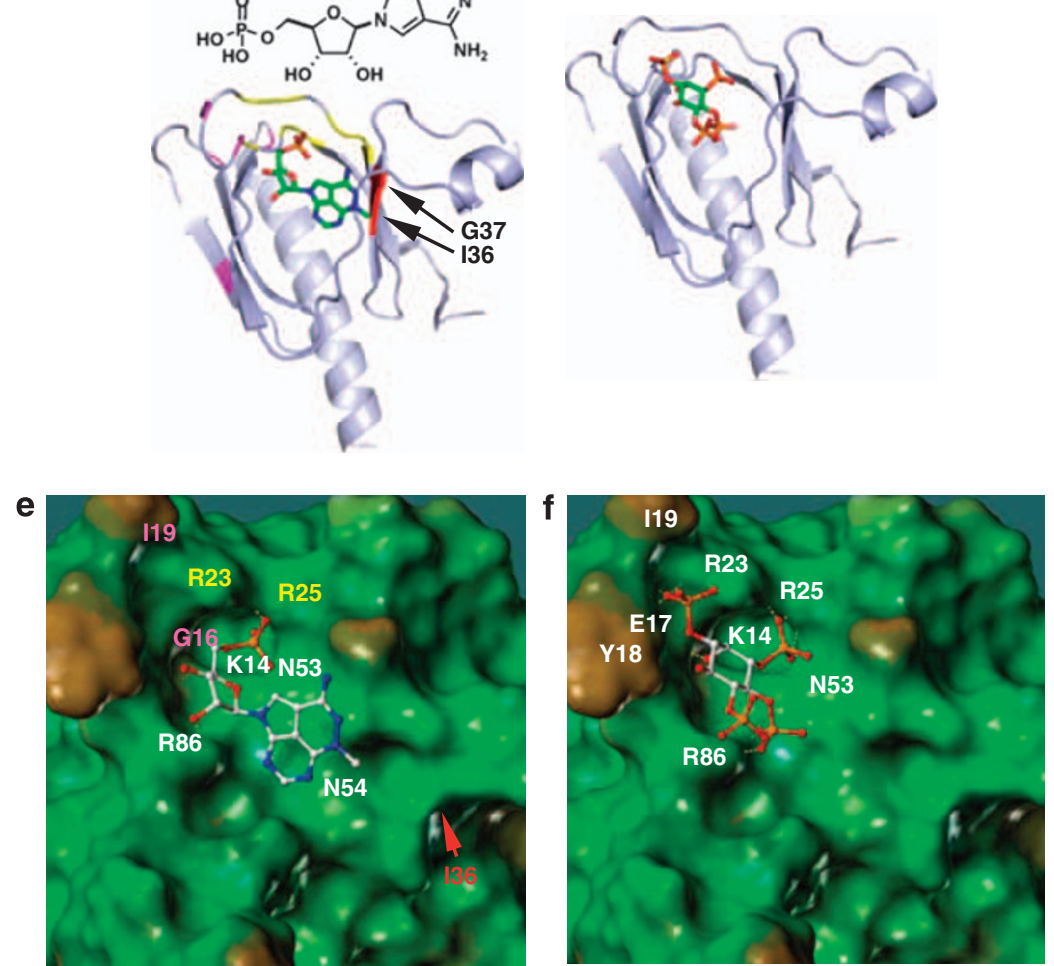

Figure 4 TCN-P, but not TCN, causes chemical shift perturbation of amino acids in the Akt PH domain. (a) Superposition of the HSQC spectra of the Akt PH domain in presence of TCN (blue) and of TCN-P (green) onto the spectrum of apo-protein (red). (b) Summary of the chemical shift perturbation values in the presence of TCN-P (gray) and TCN (green). Three dashed lines indicate $\Delta$ p.p.m. positions of 0.015, 0.03 and 0.06, respectively. (c) Structure of TCN-P (top) and model of Akt PH domain (ribbons) in complex with TCN-P (bottom). The pose of TCN-P was obtained from the docking software GOLD. The overall ribbon structures of Akt PH domain in complex with inositol $(1,3,4,5)$-tetrakisphosphate (IP4) (PDB code: $1 \mathrm{H} 10)^{36}$ were colored in gray except for residues showing significant chemical shift perturbation. These were colored based on $\Delta$ p.p.m. values: red, $\Delta$ p.p.m. $>0.06$; magenta, $0.06>\Delta$ p.p.m. $>0.03$; yellow, $0.03>\Delta$ p.p.m. $>0.015$. (d) Ribbon representation of the structure of Akt PH domain in complex with IP4 (PDB code: 1H10). ${ }^{36}$ The overall orientation is the same as that in (c). (e) Surface representation of the docking complex Akt/TCN-P and (f) of the complex Akt/IP4. In both panels, the overall surface of Akt was colored according to lipophilicity (blue, less lipophilic; brown, more lipophilic). The hydrogen bonds predicted to be formed between Akt and the compounds are shown as yellow dashed lines. The position of residues involved in the formation of hydrogen bonds is shown in white and yellow. In (e), the position of residues showing chemical shifting perturbation in (c) is also shown using the color code as in (c)

assayed in vitro the Akt1 kinase activity with GSK3- $\beta$ as substrate. TCN resulted in dose-dependent inhibition of wild-type Akt1 but not Akt1-DD kinase activity (Figure 5a, right panel). In addition to Akt1-DD, we used two other constitutively active mutants of Akt. The first is myristoylated Akt1 (myr-Akt1), which does not require its $\mathrm{PH}$ domain for plasma membrane recruitment. The other mutant of Akt is the naturally occurring, transforming mutant Akt1-E17K, which requires the $\mathrm{PH}$ domain for plasma membrane recruitment. As expected, in the absence of EGF, cells expressing wild-type Akt1 had much lower levels of phospho-Akt than those expressing either Akt1-E17K or myr-Akt1, whereas cells expressing Akt1-DD had no detectable phospho-Akt (Figure 5b). Upon stimulation with EGF, wild-type phospho-Akt levels increased and TCN treatment decreased these wild-type phospho-Akt levels. TCN also inhibited the phospho-Akt levels in cells expressing Akt1-E17K, but to a lesser degree. In contrast, TCN had no 
a

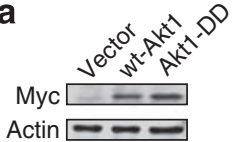

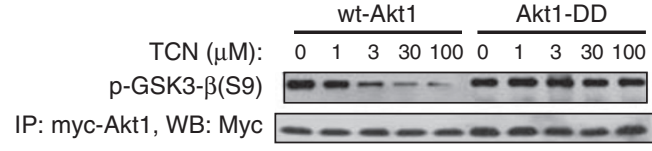

IP: myc-Akt1, WB: Myc

$$
-\infty-\infty-\infty-\infty
$$

b

\begin{tabular}{|c|c|c|c|c|c|c|c|c|c|c|c|c|c|c|c|c|}
\hline \multirow[b]{2}{*}{ TCN $(\mu \mathrm{M}):$} & \multicolumn{5}{|c|}{ wt-Akt1 } & \multicolumn{3}{|c|}{ Akt1-DD } & \multicolumn{4}{|c|}{ Akt1-E17K } & \multicolumn{4}{|c|}{ myr-Akt1 } \\
\hline & 0 & 0 & 3 & 10 & 30 & 0 & 3 & 1030 & 0 & 3 & 10 & 30 & 0 & 3 & 10 & 30 \\
\hline EGF: & - & + & + & + & + & - & - & $-\quad-$ & - & - & - & - & - & - & - & - \\
\hline
\end{tabular}

p-Akt(S473)

$-++++-\ldots$

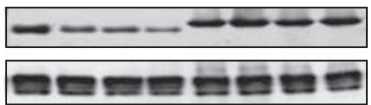

Akt $\Rightarrow----2 \equiv$

Myc $\longrightarrow 00$

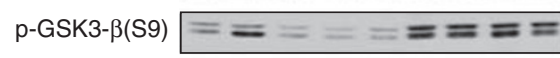

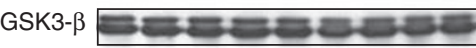

Vinculin $=-\infty-\infty+\infty$
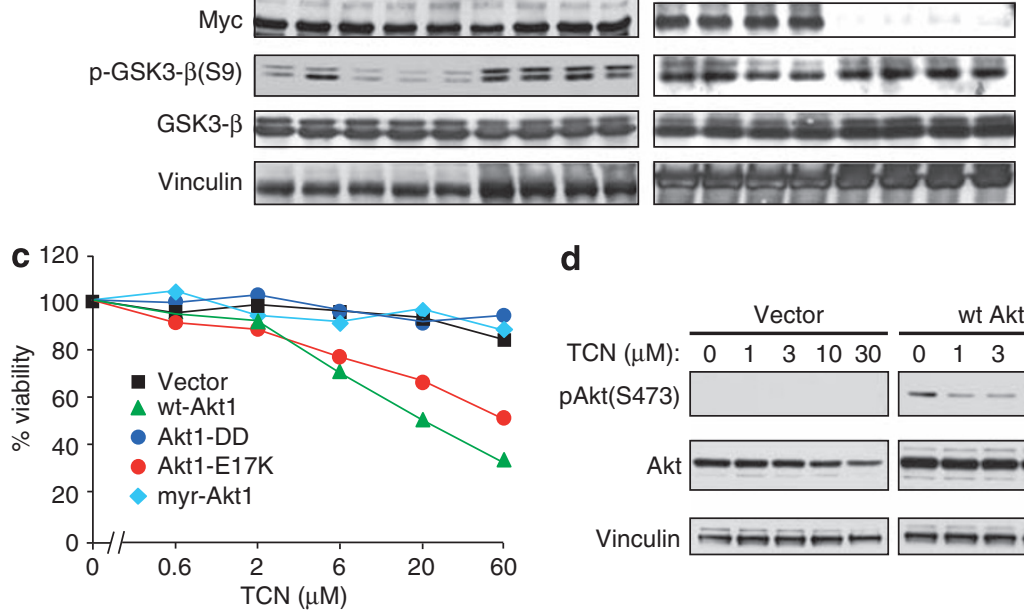

d
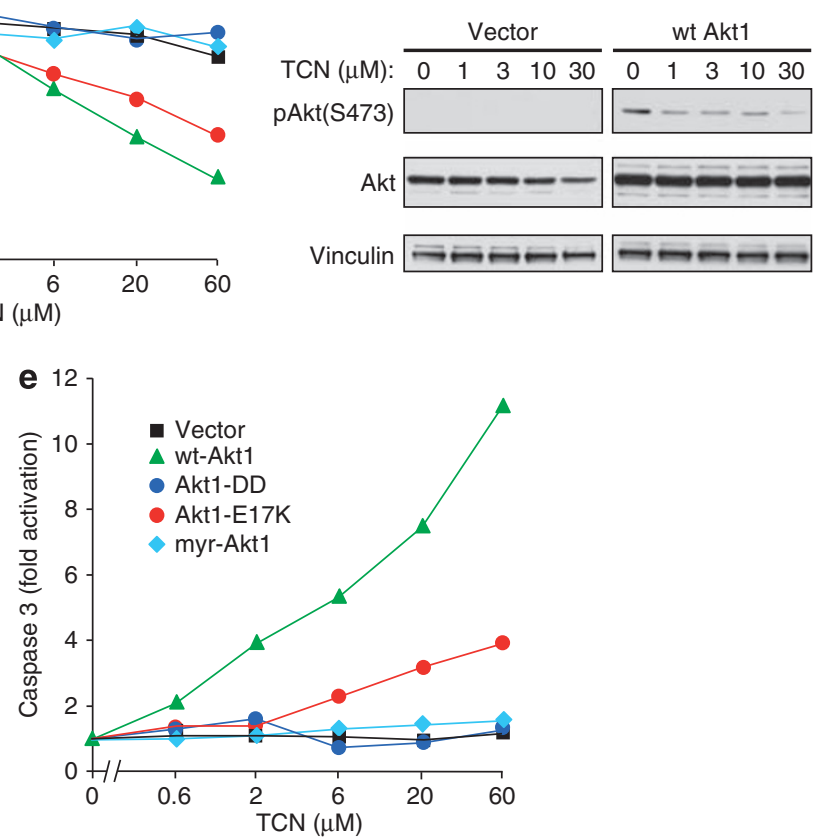

Figure 5 Constitutively active forms of Akt1 rescue cells from TCN-induced loss of viability and apoptosis. COS-7 cells expressing vector, Myc-Akt1, Myc-Akt1-DD, Myc-Akt1-E17K or myr-Akt1 were exposed to TCN. (a) The level of expression of Akt1 constructs is shown in the left panel. In the right panel, exogenously expressed Akt1 was immunoprecipitated from cells with Myc antibody, and in vitro Akt1 kinase activity was assayed by its ability to phosphorylate S9 in GSK3- $\beta$. (b) Serum-starved cells were treated with different doses of TCN for $1 \mathrm{~h}$, with or without subsequent stimulation by $30 \mathrm{ng} / \mathrm{ml}$ EGF for 20 min. Levels of endogenous phospho-Akt (S473) and phospho-GSK3- $\beta($ S9) were examined by western blotting, with vinculin serving as loading control. The Myc blots show that the recombinant proteins were being expressed at comparable levels. (c) COS-7 cells expressing Akt1 constructs were exposed to TCN for $24 \mathrm{~h}$ and then subjected to MTT assay ${ }^{41}$ to determine their proliferation/viability. The graph is representative of three independent experiments. (d) COS-7 cells have very low basal levels of phospho-Akt. To assess basal levels of S473 phosphorylation in Akt of COS-7 cells, we compared the phospho-Akt levels in COS-7 cells stably transfected with vector or wild-type Akt1, following exposure to vehicle $(0.1 \%$ DMSO, lanes 1 and 6$)$ or increasing concentrations of TCN for $24 \mathrm{~h}$. Cells were lysed as described in Materials and Methods, and analyzed by western blotting with the indicated antibodies. (e) COS-7 cells expressing vector, wt-Akt1, Akt1-DD, Akt1-E17K or myr-Akt1 were exposed to TCN for $24 \mathrm{~h}$ and then lysed. Triplicate aliquots of these lysates were analyzed by caspase-3 assay as described in Materials and Methods. This was calculated, separately for each of the three cell types, by dividing the average fluorescence intensity at a given TCN concentration by the average fluorescence intensity in the absence of TCN. The graph is representative of two independent experiments

effect on phospho-Akt levels in cells expressing myr-Akt1. Furthermore, TCN inhibited endogenous phospho-GSK3- $\beta$ in cells expressing wild-type Akt1, but not Akt1-DD or myr-Akt1. TCN inhibited phospho-GSK3- $\beta$ in Akt1-E17K expressing cells, but to a lesser degree (Figure $5 b$ ). We next determined the effect of TCN treatment for $24 \mathrm{~h}$ on the proliferation of these same cells by MTT assay. Cells transfected with vector alone were not sensitive to TCN (Figure $5 \mathrm{c}$ ). Because these cells have virtually undetectable levels of phospho-Akt (Figure $5 \mathrm{~d}$ ), this is in agreement with our previous report showing that human cancer cells low in phospho-Akt levels are less sensitive to TCN than those with high phospho-Akt levels. ${ }^{31}$ Stable expression of wild-type Akt1 rendered these cells sensitive to TCN. However, both the constitutively 
active mutants, Akt1-DD and myr-Akt1, rescued these cells from TCN-mediated inhibition of viability, whereas cells expressing Akt1-E17K were sensitive toward TCN, but not as sensitive as those expressing wild-type Akt1. Thus, Akt1-DD and myr-Akt1 are resistant to TCN and rescue from TCN effects. Consistent with these results, TCN treatment of cells expressing vector, Akt1-DD or myr-Akt1 failed to induce any noticeable caspase-3 activity, whereas cells expressing wild-type Akt1 showed a 2- to 11-fold activation of caspase-3 in response to TCN. Furthermore, in cells expressing Akt1-E17K, TCN activated caspase-3 by up to fourfold (Figure 5e). Taken together, these results suggest that TCN-induced apoptosis depends on its ability to prevent Akt phosphorylation.

\section{Discussion}

The PI3K/PTEN/Akt pathway is one of the most frequently deregulated pathways in human cancer. This justifies the need for potent and specific inhibitors capable of downregulating Akt. Targeting Akt directly would also be expected to neutralize malfunctions due to overexpression or activating mutations of PI3K and nonfunctional PTEN, which are often responsible for Akt hyperactivation. We have recently identified a compound, TCN, that has antitumor activity selectively in tumor cells that contain persistently hyperphosphorylated Akt compared with those tumors that do not. ${ }^{31}$ Because TCN does not inhibit Akt kinase activity in vitro, but prevents the phosphorylation of Akt in intact cells, TCN is thought to function as an Akt activation inhibitor rather than an Akt inhibitor, but its precise mechanism of action remains to be determined. As Akt regulation is complex (see introduction), in theory several strategies exist to inhibit Akt, such as (1) direct inhibition of Akt enzyme activity, (2) inhibition of Akt phosphorylation, (3) activation of Akt dephosphorylation or (4) prevention of Akt translocation to the plasma membrane, which is a prerequisite for the critical phosphorylations at T308 and S473. In this article, we provide evidence that TCN functions primarily through the latter mechanism.

Using SPR and NMR (see Figures 3 and 4), we have shown that TCN-P, which is known to be the active metabolite of TCN inside cells, ${ }^{33}$ can directly bind to the $\mathrm{PH}$ domain of Akt1 or Akt2. In contrast, TCN did not bind, demonstrating that the phosphate group is important for binding. The fact that TCN-P, but not TCN, binds to the PH domain of Akt supports our proposed mechanism of TCN-P competing with PIP3 and preventing Akt membrane binding. This is consistent with previous reports showing that cells unable to convert TCN to TCN-P are highly resistant to TCN. ${ }^{33}$ Furthermore, our NMR studies also showed that TCN-P, but not TCN, interacted with amino acids that are involved in PIP3 binding, which is in agreement with molecular docking studies suggesting that the Akt-PH domain PIP3-binding site can accommodate TCN-P. For example, TCN-P, but not TCN, caused chemical shifts perturbation in Akt-PH domain amino acids known to be involved in PIP3 binding. Furthermore, molecular docking shows that the phosphate group of TCN-P occupies the binding pocket of the D3 phosphate in PIP3 involving residues K14, R23, R25 and N53 of the Akt-PH domain. Finally, the sugar ring of TCN-P occupies the binding site of the six-membered ring of PIP3. Collectively, the results of SPR and NMR experiments, combined with computational docking studies, explain why TCN-P did not prevent the phosphorylation of Akt by either PDK1 or mTOR in vitro (Figure 1), but TCN prevented the translocation of Akt to the plasma membrane following EGF stimulation in intact starved cells (Figure 2). This is most likely due to TCN-P preventing PIP3 from recruiting Akt to the plasma membrane, possibly by either competing with PIP3 for binding to the Akt PH domain or binding to an adjacent pocket that induces conformational changes preventing PIP3 binding.

The behavior of the two mutants, Akt1-DD and myr-Akt1, supports this interpretation. Figure 5 shows that these forms of Akt1 do not depend on growth-factor-dependent phosphorylation for activation and suggests neither Akt1-DD nor myr-Akt1 depend on growth factor-dependent recruitment to the plasma membrane or on membrane-associated phosphorylation. Therefore, both Akt1-DD and myr-Akt1 are constitutively active. Interestingly, ectopic expression of wild-type Akt1 conferred TCN sensitivity to COS-7 cells (Figure 5c and $\mathrm{e}$ ). This is consistent with previous data that showed that parental NIH 3T3 cells are resistant to TCN whereas Akt2-overexpressing NIH 3T3 cells are sensitive to TCN. ${ }^{31}$ This is also consistent with the observation that human cancer cells with low phospho-Akt levels (OVCAR5, DU-145, T47D, Colo357, WM852) are much less sensitive than human cancer cells with high levels of phospho-Akt (OVCAR3, OVCAR8, PANC1, LNCaP, PC-3, MDA-MB-468, WM35). ${ }^{31}$ In contrast, Akt1-DD was no longer phosphorylated at T308 or S473 and its ability to phosphorylate the Akt substrate GSK3- $\beta$ was resistant to TCN. Similarly, in cells expressing myr-Akt1, TCN was unable to inhibit Akt1 phosphorylation at S473 or to inhibit phosphorylation of GSK3- $\beta$. In agreement with the failure of TCN to affect Akt phosphorylation and kinase activity, cells that express these constitutively active Akt mutants were resistant to $\mathrm{TCN}$-induced loss of viability and apoptosis. These data support the notion that the mechanism by which TCN inhibits tumor survival and growth is by preventing the phosphorylation of Akt. Furthermore, cells expressing the transforming mutant Akt1-E17K were less sensitive to TCN-induced inhibition of Akt and were also less sensitive to TCN inhibition of proliferation and induction of apoptosis. A possible explanation for the reduced sensitivity of this mutant is that replacement of a negative with a positive charge (associated with the E-to-K mutation in position 17) is predicted to result in tighter binding of Akt1-E17K to the phospholipids of the plasma membrane. ${ }^{22}$ Therefore, this would slightly reduce, but not abolish the ability of TCN to interfere with the function of Akt1-E17K.

In summary, our study data have delineated a mechanism of action for the anticancer drug and chemical probe TCN-P. This small molecule appears to function primarily by binding to the $\mathrm{PH}$ domain of Akt and preventing the recruitment of Akt to the cell membrane, where this protein is normally activated by phosphorylation. Our study results also support a mechanism of antitumor activity of TCN-P that involves inhibition of Akt phosphorylation, and suggest that in future TCN-P clinical trials, it would be important to evaluate the levels of phosphoAkt as a biomarker for TCN-P activity in patients whose tumors have high levels of phospho-Akt. 


\section{Materials and Methods}

Materials. Human recombinant Akt and PDK1 enzymes were purchased from the following companies: inactive Akt1 and active Akt1 (Invitrogen, Carlsbad, CA, USA), PDK1 (R\&D Systems, Minneapolis, MN, USA). The active version of Akt1 was phosphorylated in T308 and S473. TCN and TCN-P were obtained from the National Cancer Institute (Bethesda, MD, USA). Antibodies were from the following sources: Akt, pAkt(T308), pAkt(S473) and pGSK3- $\beta$ (S9) (Cell Signaling, Danvers, MA, USA), mTOR (Millipore, Temecula, CA, USA), E-cadherin (BD Biosciences, San José, CA, USA), GAPDH (Covance, Princeton, NJ, USA), Myc monoclonal antibody 9E10 (Santa Cruz Biotechnology, Santa Cruz, CA, USA), Alexa Fluor 594 goat anti-mouse IgG (Invitrogen), $\beta$-actin and vinculin (Sigma, St. Louis, MO, USA). EGF was purchased from Invitrogen. The caspase-3 substrate Ac-DEVD-AMC, Akt inhibitor $\mathrm{X}$ and Akt inhibitor $\mathrm{VI}$, a 15 residue peptide derived from the oncogene TCL $1,{ }^{35}$ were purchased from Calbiochem (San Diego, CA, USA). PIP3 was from Cayman Chemicals (Ann Arbor, MI, USA).

Cells and cell culture. MDA-MB-468 breast cancer cells, HEK-293T cells and COS-7 cells were grown in Dulbecco's modified Eagle's medium supplemented with $10 \%$ fetal bovine serum, and cells were maintained at $37^{\circ} \mathrm{C}$ in a humidified atmosphere containing $5 \% \mathrm{CO}_{2}$.

Generation of recombinant Akt constructs. The DNA sequence of the human Akt1 PH domain (coding for residues S2-S128, accession number: NP_005154.2) was PCR-amplified using the full-length Akt1 sequence (codonoptimized for the expression in E. coli and purchased from GeneArt, Regensburg, Germany) as a template. In the PCR reaction, the DNA oligomer ATCGCATATG GGATCCTCTGATGTTGCCATTGTTAAAGA was used as the $5^{\prime}$ end primer with Ndel and BamHI restriction sites and the DNA oligomer GCTAGCGGCCG CTTAGCTCGGGCTACCGCTACG as the $3^{\prime}$ end primer with an Nott restriction site. The PCR product was subcloned into the pET28a vector (Novagen, San Diego, CA,

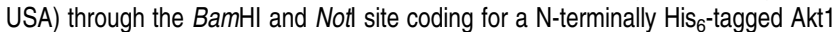
$\mathrm{PH}$ domain S2-S128 construct with a 24 residue spacer region (bold letters) between the $\mathrm{His}_{6}$ tag and the PH domain: MGSSHHHHHHSSGLVPRGSHMA SMTGGQQMGRGS-S2-PH-S128.

E. coli BL21(DE3) cells were transformed with the pET28a-His ${ }_{6}$-spacer$\mathrm{PH}(\mathrm{S} 2-\mathrm{S} 128)$ plasmid and grown at $37^{\circ} \mathrm{C}$ in 4 liter Luria Bertani medium supplemented with $30 \mu \mathrm{g} / \mathrm{ml}$ kanamycin until the cell culture showed an $\mathrm{OD}_{600}$ of 0.5-0.7. The expression of the $\mathrm{His}_{6}$-tagged PH-Akt1 construct was induced by adding $250 \mu \mathrm{M}$ isopropyl-D-thiogalactopyranoside. Cells were further incubated at $22-25^{\circ} \mathrm{C}$ for $16 \mathrm{~h}$.

Cells were collected by centrifugation and lysed by resuspension in $0.1 \mathrm{M}$ $\mathrm{Na} / \mathrm{K}$-phosphate buffer (pH 7.0), $300 \mathrm{mM} \mathrm{NaCl}, 10 \mathrm{mM}$ imidazole, $0.5 \mathrm{mg} / \mathrm{ml}$ lysozyme, $0.01 \%$ Triton $\mathrm{X}-100$. After $1 \mathrm{~h}$ incubation at $4^{\circ} \mathrm{C}$, cells were disrupted by sonication. Soluble protein was separated from cell debris and insoluble protein by centrifugation for $1 \mathrm{~h}$ at $53000 \times \mathrm{g}$. The supernatant was loaded onto an Ni-NTA column (Qiagen, Valencia, CA, USA), and the His $6_{6}$-tagged PH-Akt1 was eluted using 10 volumes of a 10-250 mM imidazole gradient. The peak fractions eluting at imidazole concentrations between 170 and $220 \mathrm{mM}$ consisted of almost pure $\mathrm{His}_{6}{ }^{-}$ tagged PH-Akt1 ( $\geqslant 98 \%)$. The fractions were pooled, and loaded onto a Superdex 200 gel filtration column (GE Healthcare, Princeton, NJ, USA) to remove misfolded aggregated protein. The $\mathrm{His}_{6}$-tagged $\mathrm{PH}$-Akt1 was concentrated to approximately $20 \mathrm{mg} / \mathrm{ml}$ using appropriate Amicon centrifugal filter units (Millipore). The concentrated protein was aliquoted, shock frozen in liquid nitrogen and stored at $-80^{\circ} \mathrm{C}$.

The phospho-mimicking constitutively active Myc-tagged Akt1-DD and the transforming mutant Akt1-E17K were generated using the PCMV-Tag3B vector and the QuikChange Site-Directed Mutagenesis Kit from Stratagene (La Jolla, CA, USA). As a template, we used human Myc-tagged wild-type Akt1 (accession number: NM_001014431.1). Myr-Akt1 was prepared as described previously. ${ }^{38}$ The DNA sequences of the wild-type and mutant cDNAs encoding the recombinant constructs were validated by our Molecular Biology Core Facility and were found to be correct.

In vitro phosphorylation assays. The effect of TCN on the phosphorylation of Akt or the kinase activity of Akt was essentially determined in two ways: by using either purified recombinant proteins or lysates or proteins immunoprecipitated from cells transfected with recombinant Akt.

Nonradioactive in vitro Akt kinase assay was performed in the presence of $200 \mu \mathrm{M}$ ATP with GSK-3 $\beta$ as a substrate according to the manufacturer's instructions (Cell Signaling), except that we used Myc antibody instead of immobilized Akt antibody to immunoprecipitate Akt.

To assess phosphorylation of Akt by PDK1, we incubated human recombinant inactive Akt1 $(30 \mathrm{ng})$ with PDK1 $(100 \mathrm{ng})$ in the presence of $200 \mu \mathrm{M}$ ATP for the indicated time at $30^{\circ} \mathrm{C}$ in a buffer consisting of $5 \mathrm{mM}$ MOPS (pH 7.2), $2.5 \mathrm{mM}$ $\beta$-glycerophosphate, $1 \mathrm{mM}$ EGTA, $0.4 \mathrm{mM}$ EDTA, $5 \mathrm{mM} \mathrm{MgCl}_{2}$ and $0.05 \mathrm{mM}$ DTT. The reaction was terminated by adding $8 \mu \mathrm{l}$ of $4 \times$ SDS sample buffer to $30 \mu \mathrm{l}$ of the reaction mixture and heating at $95^{\circ} \mathrm{C}$ for $5 \mathrm{~min}$. Samples were subjected to $10 \%$ SDS-PAGE. Phosphorylation at T308 and S473 was monitored by subsequent western blotting with the phosphorylation site-specific antibodies and developed using Chemiluminescence reagents (PerkinElmer, Boston, MA, USA).

For in vitro kinase assays following exposure of cells to TCN, we transfected cells with vector, myc-wt-Akt1, myc-Akt1-DD or myc-Akt1-E17K using LipofectAMINE2000. COS-7 cells stably transfected with these Akt1 constructs were selected by G418 (Sigma). Myr-Akt1 was transiently transfected into COS-7 cells.

The phosphorylation of Akt at $S 473$ was assayed with immunoprecipitated mTOR as described by Sarbassov et al..$^{39}$ with slight modifications. Briefly, 293T cells transfected with myc-tagged mTOR were lysed in lysis buffer containing $40 \mathrm{mM}$ HEPES (pH 7.5), $120 \mathrm{mM} \mathrm{NaCl}, 0.3 \%$ CHAPS, $1 \mathrm{mM}$ EDTA, $2.5 \mathrm{mM}$ sodium pyrophosphate, $1 \mathrm{mM} \beta$-glycerophosphate, $1 \mathrm{mM} \mathrm{Na}_{3} \mathrm{VO}_{4}$ and protease inhibitor cocktail. Lysate $(1 \mathrm{mg})$ was precleared by incubating with $20 \mu$ protein $\mathrm{G}$ Sepharose conjugated to preimmune lgG. The lysates were then incubated with $25 \mu$ l Protein $G$ and mTOR antibody. Immune complexes were incubated for $4 \mathrm{~h}$ at $4^{\circ} \mathrm{C}$ on a vibrating platform. Immunoprecipitates were washed four times with the above lysis buffer, followed by two washes with the mTOR kinase buffer (25 mM HEPES (pH 7.5), $100 \mathrm{mM}$ potassium acetate, $1 \mathrm{mM} \mathrm{MgCl}$ ). Immunoprecipitates were incubated in $30 \mu \mathrm{l}$ of the mTOR kinase buffer containing $300 \mathrm{ng}$ inactive Akt1 and $500 \mu \mathrm{M}$ ATP at $37^{\circ} \mathrm{C}$. The reaction was stopped by the addition of $8 \mu \mathrm{l}$ of $4 \times$ SDS sample buffer, and analysis of Akt phosphorylation by western blotting was performed as described above.

Immunofluorescence analyses of Akt1 membrane localization and phosphorylation. MDA-MB-468 cells growing on coverslips in six-well plates were transiently transfected with pCMV-Myc-wt-Akt1 by LipofectAMINE-2000 (Invitrogen) according to the manufacturer's instructions. At $48 \mathrm{~h}$ after transfection, cells were serum-starved overnight and treated with $20 \mu \mathrm{M} \mathrm{TCN}$ for $1 \mathrm{~h}$ and/or $100 \mathrm{ng} / \mathrm{ml}$ EGF for $15 \mathrm{~min}$. Cells were washed three times with cold phosphatebuffered saline (PBS) and fixed in $4 \%$ formaldehyde for $30 \mathrm{~min}$. Fixed cells were mounted onto glass slides with Vectashield Mounting Medium (Vector Laboratories, Burlingame, CA, USA) containing DAPI $(1.5 \mu \mathrm{g} / \mathrm{ml})$ and stained with Myc antibody $(1 \mu \mathrm{g} / \mathrm{ml})$, followed by Alexa Fluor 594-conjugated secondary antibody $(1 \mu \mathrm{g} / \mathrm{ml})$. Fluorescence was observed using a Zeiss Axiovert Upright Fluorescent microscope (Göttingen, Germany) with a $\times 60$ oil-immersion lens. For each experiment, approximately 100 Akt1-expressing cells were scored to quantify membrane localization of Akt1. We scored as positive for Myc-Akt1 membrane localization those cells whose perimeter showed a brightly red stain that was distinctly set apart from the nuclear blue DAPI stain. Results are presented as percentage of membrane-positive cells per total Akt1-expressing cells. Each bar represents the mean of three experiments \pm S.D. To assess Akt phosphorylation at S473, we used Akt antibody and phospho-Akt(S473) (193H12) Alexa Fluor 488-conjugated secondary antibody, using similar procedures as described above.

Cell fractionation. Cytosol and membrane fractions were prepared as described by Fukuda et al. ${ }^{40}$ Briefly, cells were suspended in hypotonic lysis buffer (25 mM Tris/HCl (pH 7.4), $5 \mathrm{mM}$ EDTA, $1 \mathrm{mM}$ dithiothreitol, $1 \mathrm{mM} \mathrm{Na}_{3} \mathrm{VO}_{4}$, $2.5 \mathrm{mM} \mathrm{Na}_{4} \mathrm{P}_{2} \mathrm{O}_{7}$ and protease inhibitors) and disrupted by five passages through a 27 -gauge needle. Large cell debris was pelleted by centrifugation at $2000 \times g$ for $5 \mathrm{~min}$ at $4^{\circ} \mathrm{C}$. The supernatants were centrifuged at $100000 \times \mathrm{g}$ for $20 \mathrm{~min}$ at $4^{\circ} \mathrm{C}$. The resulting supernatant (cytosol) was collected, and the pellet was washed once with hypotonic lysis buffer, then resuspended in hypotonic lysis buffer containing $1 \%$ Triton X-100. The lysate was again centrifuged at $100000 \times g$ for 20 min at $4{ }^{\circ} \mathrm{C}$, and the supernatant (membrane) was collected. The distribution of proteins in the cytosol and membrane fractions was analyzed by western blotting.

Surface plasmon resonance. The Biacore T100 instrument, the Series S sensor chips CM5 and NTA, the amine and thiol coupling kits, Biacore T100 Control and Evaluation software were purchased from GE Healthcare. The Akt inhibitor VI (reported $K_{\mathrm{D}}$ for Akt1 $\mathrm{PH}$ domain $=18 \mu \mathrm{M}^{35}$ ) was used as a positive control. 
Akt1-derived PH domain $(100 \mu \mathrm{g} / \mathrm{ml} 100 \mathrm{mM}$ sodium phosphate, $\mathrm{pH}$ 6.0) was immobilized on the active surface by ligand thiol coupling, which engages $\mathrm{SH}$ groups in the protein. In this case, a reference surface was prepared by 'blank immobilization'. All kinetic/affinity experiments were carried out at $25^{\circ} \mathrm{C}$ with at least five analyte concentrations as well as solvent alone (which served as a blank) with a flow rate of $30 \mu / / \mathrm{min}$. The contact time was typically $\geqslant 3 \mathrm{~min}$ and the dissociation time was $\geqslant 6 \mathrm{~min}$. All curves and diagrams shown are reference and blank subtracted. Compounds were prepared in running buffer, which was either PBS (for TCN-P, PIP3 and Akt inhibitor VI) or PBS containing 1\% dimethylsulfoxide (DMSO, for TCN). For each immobilization, a theoretical maximal response $\left(R_{\max }\right)$ was calculated for all compounds according to the formula: $R_{\max }=\left(\mathrm{MW}_{\text {compound }}\right.$ $\left.\mathrm{MW}_{\text {protein }}\right) \times R_{l}$, where $\mathrm{MW}=$ molecular weight and $R_{l}=$ immobilization level.

Nuclear magnetic resonance. Human Akt2 protein fragment encompassing residues 1-118 was cloned into the expression vector pGEX2T and transfected into $E$. coli. Uniformly ${ }^{15} \mathrm{~N}$-labeled protein was produced by growing the expression strain in the $\mathrm{M} 9$ medium with ${ }^{15} \mathrm{~N} \mathrm{NH}_{4} \mathrm{Cl}$ as the sole nitrogen source. The protein was purified using GST affinity chromatography and then cleaved with thrombin. The resulting protein product has two extra amino-acid residues (GS) at the $\mathrm{N}$ terminus. The NMR samples contained $100 \mathrm{mM}$ of protein in $100 \mathrm{mM}$ phosphate buffer $(\mathrm{pH} 7.0)$ in $95 \% \mathrm{H}_{2} \mathrm{O} / 5 \% \mathrm{D}_{2} \mathrm{O}$. All NMR experiments were performed at $300 \mathrm{~K}$ on a $700 \mathrm{MHz}$ Bruker Avance III spectrometer (Billerica, MA, USA) equipped with a triple-resonance cryoprobe.

Molecular docking studies. The docking studies of Akt2 and TCN-P were performed using the program GOLD version 2.1. The structure of Akt in complex with IP4 (PDB code: $1 \mathrm{H} 10)^{36}$ was adopted to prepare the docking studies. The TCNP-binding site was defined within a $15 \AA$ radius around the residue $\mathrm{K} 14$. A total of 100 runs were performed and the conformation of TCN-P with the best GOLD score was selected for display.

Caspase-3 activation assay. A total of 300000 COS-7 cells expressing vector, wild-type Akt1, Akt1-DD, Akt1-E17K or myr-Akt1 were exposed to TCN for $24 \mathrm{~h}$, lysed in a buffer consisting of $50 \mathrm{mM}$ tris/Cl (pH 7.5), $5 \mathrm{mM}$ EDTA, $150 \mathrm{mM}$ $\mathrm{NaCl}$ and $0.5 \% \mathrm{NP}-40$. Lysate containing $20 \mu \mathrm{g}$ protein was then incubated in triplicate for $1 \mathrm{~h}$ at $37^{\circ} \mathrm{C}$ with $20 \mu \mathrm{M}$ of the fluorogenic caspase-3 substrate Ac-DEVD-AMC in the presence of $50 \mathrm{mM}$ tris/Cl (pH 7.5) in a total volume of $100 \mu \mathrm{l}$ Fluorescence was monitored with a Wallac Victor2 multiplate reader (excitation: $355 \mathrm{~nm}$, emission: $460 \mathrm{~nm}$ ).

\section{Conflict of interest}

The authors declare no conflict of interest.

Acknowledgements. This work was funded in part by $\mathrm{NIH}$ Grants RO1CA098473 (to SMS), P01-CA128814 and U54 HG005033 (to MP). We thank the Microscopy, High-Throughput Screening and Molecular Biology Core Facilities at the Moffitt Cancer Center for their expert technical assistance.

1. Jones PF, Jakubowicz T, Pitossi FJ, Maurer F, Hemmings BA. Molecular cloning and identification of a serine/threonine protein kinase of the second-messenger subfamily. Proc Natl Acad Sci USA 1991; 88: 4171-4175.

2. Coffer PJ, Woodgett JR. Molecular cloning and characterisation of a novel putative proteinserine kinase related to the CAMP-dependent and protein kinase $C$ families. Eur J Biochem 1991; 201: 475-481.

3. Bellacosa A, Testa HR, Staal SP, Tsichlis PN. A retroviral oncogene, akt, encoding a serine-threonine kinase containing an SH2-like region. Science 1991; 254: 274-277.

4. Manning BD, Cantley LC. AKT/PKB signaling: navigating downstream. Cell 2007; 129 : 1261-1274

5. Qiao M, Sheng S, Pardee AB. Metastasis and AKT activation. Cell Cycle 2008; 7: 2991-2996.

6. Chen WS, Xu PZ, Gottlob K, Chen ML, Sokol K, Shiyanova T et al. Growth retardation and increased apoptosis in mice with homozygous disruption of the akt1 gene. Genes Dev 2001; 15: 2203-2208

7. Cho $H$, Thorvaldsen JL, Chu Q, Feng F, Birnbaum MJ. Akt1/PKB $\alpha$ is required for normal growth but dispensable for maintenance of glucose homeostasis in mice. $\mathrm{J}$ Biol Chem 2001; 276: 38349-38352.
8. Cho H, Mu J, Kim JK, Thorvaldsen JL, Chu QW, Crenshaw lii EB et al. Insulin resistance and a diabetes mellitus-like syndrome in mice lacking the protein kinase Akt2 (PKB $\beta)$. Science 2001; 292: 1728-1731.

9. Easton RM, Cho H, Roovers K, Shineman DW, Mizrahi M, Forman MS et al. Role for Akt3/protein kinase $B \gamma$ in attainment of normal brain size. Mol Cell Biol 2005; 25: 1869-1878

10. Alessi DR, James SR, Downes CP, Holmes AB, Gaffney PRJ, Reese CB et al. Characterization of a 3-phosphoinositide-dependent protein kinase which phosphorylates and activates protein kinase $\mathrm{B} \alpha$. Curr Biol 1997; 7: 261-269.

11. Feng J, Park J, Cron P, Hess D, Hemmings BA. Identification of a PkB/Akt hydrophobic motif Ser-473 kinase as DNA-dependent protein kinase. J Biol Chem 2004; 279: $41189-41196$.

12. Bozulic L, Surucu B, Hynx D, Hemmings BA. PKB $\alpha /$ Akt1 acts downstream of DNA-PK in the DNA double-strand break response and promotes survival. Mol Cell 2008; 30: 203-213.

13. Sarbassov DD, Guertin DA, Ali SM, Sabatini DM. Phosphorylation and regulation of Akt/PKB by the Rictor-mTOR complex. Science 2005; 307: 1098-1101.

14. Alessi DR, Andjelkovic M, Caudwell FB, Cron P, Morrice N, Cohen P et al. Mechanism of activation of protein kinase B by insulin and IGF-1. EMBO J 1996; 15: 6541-6551.

15. Ugi S, Imamura T, Maegawa H, Egawa K, Yoshizaki T, Shi K et al. Protein phosphatase $2 \mathrm{~A}$ negatively regulates Akt (protein kinase B) activity in 3T3-L1 adipocytes. Mol Cell Biol 2004; 24: 8778-8789.

16. Xu W, Yauan X, Jung YJ, Yang Y, Basso AD, Rosen $\mathrm{N}$ et al. The heat shock protein 90 inhibitor geldanamycin and the ErbB inhibitor ZD1839 promote rapid PP1 phosphatasedependent inactivation of AKT in ErbB2 overexpressing breast cancer cells. Cancer Res 2003; 63: 7777-7784.

17. Brognard J, Newton AC. PHLiPPing the switch on Akt and protein kinase $C$ signaling Trends Endocrinol Metab 2008; 19: 223-230.

18. Dillon RL, White DE, Muller WJ. The phosphatidyl inositol 3-kinase signaling network: implications for human breast cancer. Oncogene 2007; 26: 1338-1345.

19. Liu W, Bagaitkar J, Watabe K. Roles of AKT in breast cancer. Front Biosci 2007; 12: 4011-4019.

20. Sun M, Wang J, Pacigga JE, Feldman RI, Yuan Z-Q, Ma X-L et al. Akt1/PKB $\alpha$ kinase is frequently elevated in human cancers and its constitutive activation is required for oncogenic transformation in NIH3T3 cells. Am J Pathol 2001; 159: 431-437.

21. Sun M, Paciga JE, Feldman RI, Yuan Z-Q, Coppola D, Lu YY et al. Phosphatidylinositol-3-OH kinase (PI3K)/AKT2, activated in breast cancer, regulates and is induced by estrogen receptor $\alpha(E R \alpha)$ via interaction between $E R \alpha$ and PI3K. Cancer Res 2001; 61: 5985-5991.

22. Carpten JD, Faber AL, Horn C, Donoho GP, Briggs SL, Robbins CM et al. A transforming mutation in the pleckstrin homology domain of AKT1 in cancer. Nature 2007; 448: 439-445.

23. Liu X, Shi Y, Han EK, Chen Z, Rosenberg SH, Giranda VL et al. Downregulation of Akt1 inhibits anchorage-independent cell growth and induces apoptosis in cancer cells. Neoplasia 2001; 3: 278-286.

24. Arboleda MJ, Lyons JF, Kabbinavar FF, Bray MR, Snow BE, Auyala R et al. Overexpression of $\mathrm{AKT} 2 /$ protein kinase $\mathrm{B} \beta$ leads to up-regulation of $\beta 1$ integrins, increased invasion, and metastasis of human breast and ovarian cancer cells. Cancer Res 2003; 63: 196-206.

25. Stahl JM, Sharma A, Cheung M, Zimmermann M, Cheng JQ, Bosenberg MW et al. Deregulated Akt3 activity promotes development of malignant melanoma. Cancer Res 2004; 64: 7002-7010.

26. Liang J, Slingerland JM. Multiple roles of the PI3K/PKB (Akt) pathway in cell cycle progression. Cell Cycle 2003; 2: 339-345.

27. Bozulic L, Hemmings BA. PIKKing on PKB: regulation of PKB activity by phosphorylation. Curr Opin Cell Biol 2009; 21: 256-261.

28. Gonzalez E, McGraw TE. The Akt kinases: isoform specificity in metabolism and cancer. Cell Cycle 2009; 8: 2502-2508.

29. Cheng JQ, Lindsley CW, Cheng GZ, Yang H, Nicosia SV. The Akt/PKB pathway: molecular target for cancer drug discovery. Oncogene 2005; 24: 7482-7492.

30. Hennessy BT, Smith DL, Ram PT, Lu Y, Mills GB. Exploiting the PI3K/Akt pathway for cancer drug discovery. Nat Rev Drug Discov 2005; 4: 988-1004.

31. Yang L, Dan HC, Sun M, Liu QY, Sun XM, Feldman RI et al. Akt/protein kinase B signaling inhibitor-2, a selective small molecule inhibitor of Akt signaling with antitumor activity in cancer cells overexpressing Akt. Cancer Res 2004; 64: 4394-4399.

32. Schweinsberg PD, Smith RG, Loo TL. Identification of the metabolites of an antitumor tricyclic nucleoside (NSC-154020). Biochem Pharmacol 1981; 30: 2521-2526.

33. Wotring LL, Crabtree GW, Edwards L, Parks Jr RE. Mechanism of activation of triciribine phosphate (TCN-P) as a prodrug form of TCN. Cancer Treat Rep 1986; 70: 491-497.

34. Garrett CR, Coppola D, Wenham RM, Cubitt CL, Neuger AM, Frost TJ et al. Phase I pharmacodynamic study of triciribine phosphate, a small molecule inhibitor of Akt phosphorylation, in adult subjects with solid tumors containing phosphorylated Akt In: 10th Annual AACR Meeting Denver, CO, 2009.

35. Hiromura M, Okada F, Obata T, Auguin D, Shibata T, Roumestand C et al. Inhibition of Akt kinase activity by a peptide spanning the $\beta$ A strand of the proto-oncogene TCL1. J Biol Chem 2004; 279: 53407-53418. 
36. Thomas CC, Deak M, Alessi DR, van Aalten DM. High-resolution structure of the pleckstrin homology domain of protein kinase b/Akt bound to phosphatidylinositol $(3,4,5)$ trisphosphate. Curr Biol 2002; 12: 1256-1262.

37. Auguin D, Barthe P, Auge-Senegas MT, Stern MH, Noguchi M, Roumestand C. Solution structure and backbone dynamics of the pleckstrin homology domain of the human protein kinase B (PKB/Akt). Interaction with inositol phosphates. J Biomol NMR 2004; 28: 137-155.

38. Bellacosa A, Chan TO, Ahmed NN, Datta K, Malstrom S, Stokoe D et al. Akt activation by growth factors is a multiple-step process: the role of the PH domain. Oncogene 1998; 17: 313-325.
39. Sarbassov DD, Ali SM, Sengupta S, Sheen JH, Hsu PP, Bagley AF et al. Prolonged rapamycin treatment inhibits mTORC2 assembly and Akt/PKB. Mol Cell 2006; 22: 159-168.

40. Fukuda T, Guo L, Shi X, Wu C. CH-ILKBP regulates cell survival by facilitating the membrane translocation of protein kinase B/Akt. J Cell Biol 2003; 160 : 1001-1008.

41. Kazi A, Lawrence H, Guida WC, McLaughlin ML, Springett GM, Berndt N et al. Discovery of a novel proteasome inhibitor selective for cancer cells over non-transformed cells Cell Cycle 2009; 8: 1940-1951. 